\title{
STAGES OF SMOKING CESSATION AMONG ADULT CURRENT SMOKERS IN MALAYSIA: FINDINGS FROM THE NATIONAL E-CIGARETTE SURVEY 2016
}

\author{
${ }^{*}$ Lim Kuang Hock${ }^{1}$.Sumarni Mohd Ghazali ${ }^{1}$, Lim Hui $\mathrm{Li}^{2}$, ' Heng Pei ${ }^{1}$, Kee Chee Cheong ${ }^{3}$,Teh Chien Huey ${ }^{1}$, \\ Cheah Yong Kang ${ }^{4}$ and Lim Jia Hui ${ }^{5}$ \\ 1 Institute For Medical Research, Ministry of Health Malaysia, Jalan Pahang, 50588, Kuala Lumpur. \\ ${ }^{2}$ Hospital Sultan Ismail, Ministry of Health Malaysia,Jalan Mutiara Emas Utama, Taman Mount Austin, 81100 Johor Bahru, \\ Johor \\ ${ }^{3}$ National Institute of Health, Ministry of Health Malaysia,Bandar Setia Alam, 40170, Shah Alam, Selangor.. \\ ${ }^{4}$ School of Economics, Finance and Banking College of Business, Universiti Utara Malaysia 06010 UUM Sintok, Kedah. \\ ${ }^{5}$ Monash University Malaysia, Jalan Lagoon Selatan, Bandar Sunway, 47500 Subang Jaya, Selangor
}

${ }^{*}$ Correspondence Author: Lim Kuang Hock

Email: limkh@moh.gov.my

\begin{abstract}
Identification of the stages of smoking cessation among smokers is essential to improve the rate of smoking cessation. The aims of this study were to determine the prevalence and factors associated with stages of smoking cessation across the demographic distribution of adult smokers in Malaysia. Data were derived from a population-based study among Malaysian adults aged 18 years and above. Face-to-face interviews were carried out by trained staff using a validated questionnaire to obtain data related to smoking from 4,288 selected respondents. Of 4,288, 438 respondents are current smokers. Multivariable logistic regression analysis was used to determine factors associated with stage of smoking cessation. Approximately 60\% ( $n=269 / 438)$ of the current smokers were in the pre-contemplation stage and 40\% ( $n=169 / 438)$ were in the contemplation and preparation stages of smoking cessation. The proportion of pre-contemplators was higher among smokers with higher levels of nicotine addiction (71.3\%), lower education attainment (71.4\%), and those who were single/widowed/divorced (66.9\%). Multivariable analysis showed that males, and those who reported low to high level of nicotine addiction were more likely to be in the pre-contemplation stage whilst those in the older age groups were more likely to be in the advanced stage of smoking cessation. The study revealed that the majority of current smokers in Malaysia had no intention to quit smoking within 6 months. Specific interventions targeting males, young adults and smokers with low to high nicotine addiction should be introduced to ensure the smokers proceed to the advanced stage of smoking cessation.
\end{abstract}

Keywords: Smoking cessation, addiction level, Malaysian adult smokers, ECV.

\section{INTRODUCTION}

Chronic illness and mortality related to smoking are among the major public health problems globally and locally. ${ }^{1,2}$ Diseases related to the smoking are a major contributor to the burden of diseases and mortality for the past three decades in Malaysia. ${ }^{3}$ Annually, it has been estimated that one third of the years of life lost (YLL), one-fifth of disabilityadjusted life years (DALYs) and 20,000 deaths are due to smoking-related diseases. ${ }^{4,5}$

Increasing the smoking cessation rate is among the strategies stipulated in the national anti-smoking program to reduce smoking prevalence in Malaysia. ${ }^{6}$ Activities and measures such as health promotion, denormalization of smoking through the expansion of smoke free public areas, increasing the price of tobacco products, provision of smoking cessation service in public primary health care facilities and hospitals under the purview of $\mathrm{MOH}$ as well as private clinics had been introduced and implemented to achieve the stipulated objectives. The measures implemented were in line with the provision of several articles of the Framework Convention of Tobacco Control (FCTC), which urge signatories to reduce the demand for tobacco products, provide support for reducing nicotine dependence and to increase the rate of smoking cessation. $^{7}$

Findings from epidemiological studies have shown that integration of behavioral components into smoking cessation programs may significantly increase smoking cessation..$^{8,9}$ The trans-theoretical model (TTM) of change by Prochaska et al. (1992) ${ }^{10}$ is one of the widely used theories on human behavior. ${ }^{11,12,13}$ Higher predictive of the theory, analysing profiles of subjects by stage over time, and determine the suitable strategy or health education approach to be implemented for individuals or groups within a population in different stages of smoking cessation were among the factors of the theory been widely utilised. The TTM theory posits that smoking cessation is a 
process of movement through five stages of motivation, namely: (a) Pre-contemplation -the smoker has no intention to cease smoking within six month), (b) Contemplation- (the smoker intends to quit smoking within 6 months), (c) Preparation (the smoker plans to quit smoking within 30 days), (d) Action (the smoker has not smoked in the past 6 months), and (5) Maintenance (the smoker has ceased smoking for more than 6 months to 5 years). The theory asserts that before smokers are able to successfully quit smoking, they have to progress from the "pre-contemplation" to "contemplation" and "preparation" stages.

In addition to the investigation of the effectiveness of TTM behavioural theory, investigation on the prevalence and factor/s associated with the stages of smoking cessation of the theory were also extensively carried out in order to enhance the rate of successful smoking cessation by expediting the progress through smoking cessation stages. Ma et al. (2003) revealed that older smokers of AsianAmerican descent tend to be at the advance stages of smoking cessation. ${ }^{14}$ John et al (2003) in their study on a representative sample of German smokers reported that the stages of smoking cessation did not differ according to gender or age. ${ }^{15}$ However, more smokers with at least 16 years of education were contemplators than those without such education attainment. Lower nicotine dependence were found to be significantly associated with advanced stages of smoking cessation among Arabian adult smokers. ${ }^{16}$ Additionally, usage of e-cigarettes which is a recently introduced product as alternatives to cigarette had been reported to be significantly associated with intention to cease smoking. ${ }^{17,18}$ Furthermore, Mathur and Singh (2015) $)^{19}$ and Soulakeva et al (2016) ${ }^{20}$ reported that certain ethnic groups such as non-Hispanic blacks in America had higher odds or were more willing to cease smoking within six months as compared to other ethnicities in America such as American Asians and nonHispanic whites.

There is only one report available on stage of smoking cessation in Malaysia since 2000. Lim and colleague (2013) ${ }^{21}$, using data from the third National Health and Morbidity Survey (NHMS) 2006, reported that $70 \%$ of adult smokers in Malaysia planned to cease quit smoking within six months. Female gender, higher education attainment and smoking fewer cigarettes were significantly associated with contemplation to quit smoking. However, the study did not investigate nicotine addiction level which has been associated to smoking cessation. In addition, changes in the social and demographic structure of the Malaysian population during the past decade might affect the validity of the finding and its generalizability to the current Malaysian population. Furthermore, the more recent introduction and use of e-cigarettes, and rigorous anti-smoking efforts and measures by the Malaysian government after it ratified the Framework convention on Tobacco Control (FCTC) might also influence the intention and stages of smoking cessation among Malaysian adult smokers. This write-up is intended to provide the latest information on stages of smoking among a representative sample of Malaysian adult smokers aged 18 years and above using the latest data from a population-based survey on e-cigarettes in 2016, as current knowledge on stages of smoking cessation is urgently needed to assist in formulation or changes in the smoking cessation program.

\section{METHODOLOGY}

Data was derived from the National Electronic Cigarette Survey (NECS) 2016, which was carried out from April 2016- June 2016. The study design was cross-sectional, using two-stage proportionate-tosize sampling to select a representative sample of the Malaysian population aged 18 years and above. In the first stage, strata consisted of fifteen states in Malaysia followed by stratification of urban and rural areas for each state. Each stratum consisted of enumeration blocks (EBs) which are artificial geographic units created by the Department of Statistics (DOS). The EBs were the primary sampling units. Each EB consisted of 80-120 living quarters based on 2010 population census. The secondary sampling units were living quarters (LQs), and 12 LQs were selected from each selected EB. All eligible household members aged 18 years and above in the selected LQs were invited to participate in the study. A total of 3,494 LQs were selected for the study $(2,028$ from urban and 1,466 from rural areas). A total sample size of 5722 was determined based on a previous study (Global adult tobacco survey-GATS ${ }^{22}$ and expert opinion of a $3 \%$ prevalence, precision of $1.5 \%$ design effect of 2 , two-stage sampling method and $20 \%$ non-response rate.

Trained research assistants (RA) conducted face-toface interviews to obtain data from the selected respondents. Prior to the interview session, the RA explained the purpose of the study to the respondents, voluntary participation, and assurance of the respondent's right not to answer any questions and freedom to withdraw at any juncture from the study. In addition, respondents were assured that all information given will be kept confidential and will be utilised for research purposes only. The interview session commenced only after written consent had been obtained from the respondents. Ethical approval for the study was granted by the Medical Research and Ethics 
Committee, Ministry of Health, Malaysia (NMRR-16171-28819 [IIR]). A detailed description of the study can be found in the National e-Cigarette Survey report. ${ }^{23}$ The study instrument was adapted from GATs ${ }^{22}$ and National Health and Morbidity survey $(\mathrm{NHMS})^{24}$ and validated by a panel of experts consisting of public health specialists, researchers, and academicians with experience in tobacco studies. The questionnaire consisted of 8 components: social-demographic background, awareness and usage of e-cigarette, cigarette smoking status, exposure to EC smoke/vapour, exposure to e-cigarettes promotion and antismoking campaign, perception of e-cigarettes, and e-cigarette liquid analysis. The instrument was tested in both urban and rural settings in March 2016 involving 120 adult respondents who were equally distributed by gender, smoking status and age group with the purpose of establishing face validity. Minor correction of the questionnaire was carried out based on feedback from the respondents.

\section{Measures}

Smoking status of respondents was measured by the following items: (1) Have you ever smoked a cigarette in your lifetime? (2) Have you ever smoked 100 sticks of cigarettes in your life time and (3) Do you currently smoke cigarettes? Respondents who answered "Yes" to all three items were categorized as current smokers, respondents who answered "Yes" to the item 1 and "No" to items 2 and 3 were classified as ever smokers, and those who answered "Yes" to items 1 and 2 and "No" to item 3 were exsmokers. ${ }^{24}$ Non-smokers were those answered "No to all three items. Only current smokers were included in this analysis.

The dependent variable was stage of smoking cessation, which was measured by the item "I intend to quit smoking...", with the following response options: (a) Within a month, (b) Within the next 3 months, (c) Within the next 6 months, (d) Within the next 12 months, (e) No intention to quit. Those who intended to quit smoking within a month were categorized as in the preparation stage, within next 3 month and six months in contemplation stage, while within next 12 months and no intention to quit as in pre-contemplation stage. Respondents in the preparation and contemplation stages were combined into a single category (contemplation and preparation stage) in view of small number of respondents in preparation stage. 10 Social demographic characteristics included in the study wer1e gender, ethnicity (Malay, Chinese, Indian, Others), education attainment (No formal education, completed primary education, completed secondary school and completed university/college), age group (15-24 years old, 2544 years old , 45-64 years old 65+), locality (urban/ rural), marital status (single widow/widower/separated and married) and type of occupation (government employee, private sector employee, self-employed and others). Status of current e-cigarette use was measured by an item (Are you currently using e-cigarette, or vape? "Yes/No"), while nicotine addiction was measured the Fagerstrom Test for Nicotine Dependence (FTND) which has been validated. ${ }^{25}$

FTND consisted of six items, (a) How soon after you wake up do you smoke your first cigarette? Within 5 minutes (score-3), 6 to 30 minutes (score $=2$ ), 31-60 minutes (score $=1$ ) and after 60 minutes (score-0) $(b)$ Do you find it difficult to refrain from smoking in places where it is forbidden (e.g., in church, at the library, in the cinema)? (Score 0 for and 1 for yes) (c) Which cigarette would you hate most to give up? (The first one in the morning (score=1), Any other $($ score $=0)($ d) How many cigarettes per day do you smoke? $(10$ or less (score $=0), 11-20$ (score $=1), 21-30$ (score=2), $\geq 31$ or more (score=3) (e) do you smoke more frequently during the first hours after waking than during the rest of the day? (Yes (score $=1$ ), No $($ score $=0))(f)$ Do you smoke when you are so ill that you are in bed most of the day? Yes (score=1), No $($ score $=0)$. Total score ranged from 0-10. Nicotine addiction status was further categorized as "None to very low" (scores from 0-2), or "Low to high addiction" (scores from 3-10). This definition of the stages of smoking cessation has been validated and has been used in many studies in other countries, $14,15,19,20$ therefore the results of this study can be compared across these studies.

\section{Statistical analysis}

Data were cleaned prior to analysis. Descriptive statistics was used to describe the social demographic variation of respondents. Chi square analysis was used to test for associations between stage of smoking and social demographic variables, nicotine addiction level and ECV use. Multivariable logistic (backward stepwise selection method based on likelihood ratio statistic) was used to test the independent associations (controlling for confounders) of various social-demographic characteristics, level of nicotine addiction, and ecigarettes use with stage of smoking cessation. The final model was tested by the Hosmer-Lemeshow test, which yielded a p-value of 0.154 , indicating that the model fitted well. All statistical analyses were run at $95 \%$ confidence level using SPSS statistical software version 16 .

\section{RESULTS}

Almost two thirds of Malaysian current smokers were in the pre-contemplation stage. Proportion of pre-contemplators was significantly higher among female compared to male smokers $(88.9 \%$ vs. $60.3 \%$, 
$\mathrm{p}=0.015$ ), and those with low to high nicotine addiction compared to those who had none to very low addiction (71.3\% vs $53.7 \%)$. Smokers in the older age group were more likely than younger smokers to be in advanced stages (contemplation and preparation) of smoking cessation. In addition, the proportion of smokers who intended to cease smoking within six months was higher among those with tertiary education and married compared to their lower educated and single or widowed counterparts. However, no significant association was observed between ECV use, residential area, ethnicity and type of occupation with stages of smoking cessation (Table 1).

Multivariable logistic analysis revealed that smokers with higher addiction level (AOR $2.10,95 \% \mathrm{Cl}$ 1.37$3.27)$ and male (AOR $5.32,95 \% \mathrm{Cl} 1.10-24.39)$ were more likely to be in pre-contemplation stage, whilst those in the older age group (AOR $0.57,95 \% \mathrm{Cl} 0.37$ 0.80 ) were more likely to cease smoking within 6 months. Other independent variables were not significantly associated with stage of smoking cessation after the effects of others independent variables were controlled for in multivariable analysis (Table 2 ).

\section{DISCUSSION}

The study revealed that almost two thirds (61.5\%) of current smokers in Malaysia were in the precontemplation stage of smoking cessation. The proportion of pre-contemplators is almost similar to among current smokers of Arab descent in Israel $(61.8 \%)^{16}$ but higher than among adult smokers in Vietnam (52.3\%), ${ }^{26}$ Korea $(37.6 \%)^{12}$ and Australia (adult aborigines $39.6 \%$ ) $^{27}$ and, lower than in six cities in China $(76.4 \%)^{28}$ and the Global Adult Tobacco Survey's 21-country average prevalence (74.8\%). ${ }^{29}$ The differences between countries may be due to differences in the stage of smoking epidemic in each country. Malaysia is in Stage 2 of a tobacco epidemic while other countries are in stage 3 or $4 .{ }^{30}$ They may also be due to differences in tobacco control measures between countries. High income countries like USA or South Korea have had much longer histories of tobacco control compared to Malaysia. ${ }^{12,31}$ These countries have implemented smoke-free policies in workplaces and public venues much earlier and have much more extensive anti-smoking campaigns and cessation services which might influence smokers' intention to quit as suggested by the social ecological theory that the law (mesosystem) is one of the contributing factors influencing human behavior in society. ${ }^{32}$

The proportion of pre-contemplators in our study was approximately twice as high as in $2013^{21}$ (30\%). We postulate that such a large increase in the proportion of pre-contemplators might be due to the difference in the definition of current smoking. The NHMS 2006 defined current smoking as smoking at least a puff of cigarette in the past 30 days, ${ }^{24}$ while in the current study defined smoking as those who currently smoked. The vast difference in the proportion of pre-contemplators might also be due to changes in the characteristics of Malaysian smokers in the past ten years such as changes in addiction level. The higher proportion of smokers in the pre-contemplation stage is especially worrying as smoking prevalence has not changed in the past ten years, while the proportion of smokers in advanced stages of smoking cessation has dropped substantially.

These results indicate an urgent need for more comprehensive and aggressive smoking cessation programs or other intervention measures, such as augmenting health promotion activities to increase smokers' awareness and interest in attending in smoking cessation clinics to ensure more smokers proceed to advanced stages of smoking cessation. In addition, the finding also suggests that the smoking cessation strategies and measures implemented in Malaysia should focus on smokers in the precontemplation stage, or who have no intention to quit smoking in the near future.

Female smokers were more likely to be in advanced stages of smoking cessation compared to their male counterparts in multivariable analysis. This finding concurs with studies by Lim et al. $(2013)^{21}$ and Driezen et al. (2016) ${ }^{33}$ who reported that more female smokers have intention to cease smoking (78\%) compared to male smokers (AOR 1.78 (95\% Cl: 0.77-4.10, $p=175)$ ). In contrast, John et al. $(2003)^{15}$ and Feng et al $(2010)^{28}$ revealed that the proportion of contemplators in Germany and China did not vary by gender. Previous studies highlighted emotion and stress as important factors in continued tobacco use among female smokers. ${ }^{38}$ More and more women are joining the workforce in recent history. Working women might have more difficulties, negative emotions and additional stress in balancing family and work, which make them less likely to quit smoking compared to men. ${ }^{34}$ However, we did not find such factors influencing the female smokers in our study, probably because men are more compelled to continue to smoke as a means of responding to social stimuli. In contrast, females are less compelled to smoke, as smoking among females is not a social norm in Malaysia. ${ }^{35}$ Furthermore, in communal societies such as in Malaysia, the opinions and norms of the community precedes those of individuals. Therefore, social stigma and collective community-based consciousness may compel female smokers to contemplate quitting smoking to ensure conformity to community norms and opinions. 
Table 1: Stages of smoking cessation among Malaysian Adults aged 18 years and above

\begin{tabular}{|c|c|c|c|c|}
\hline \multirow[t]{2}{*}{ Variable } & \multicolumn{2}{|c|}{$\begin{array}{c}\text { Overall } \\
\text { Stages of smoking Cessation }\end{array}$} & \multirow{2}{*}{$\begin{array}{l}\text { Chi } \\
\text { value }\end{array}$} & \multirow[t]{2}{*}{ squarep value } \\
\hline & $\begin{array}{c}\text { Pre-contemplation } \\
\mathrm{n}(\%)\end{array}$ & $\begin{array}{l}\text { Contemplation and } \\
\text { preparation } \mathrm{n}(\%)\end{array}$ & & \\
\hline Overall & $270(61.5)$ & $169(38.5)$ & & \\
\hline \multicolumn{5}{|l|}{ Gender } \\
\hline Male & $254(60.3)$ & 167(39.7) & 5.95 & 0.015 \\
\hline Female & $18(88.9)$ & $2(11.1)$ & & \\
\hline \multicolumn{5}{|l|}{ Ethnicity } \\
\hline $\begin{array}{l}\text { Malay and } \\
\text { others Bumiputras }\end{array}$ & $258(61.6)$ & $161(38.4)$ & 0.10 & 0.747 \\
\hline Chinese and Indian & $11(57.0)$ & $8(42.1)$ & & \\
\hline \multicolumn{5}{|l|}{ Marital Status } \\
\hline Married & 167(58.6) & $118(41.4)$ & 2.90 & 0.089 \\
\hline Single, widowew & 103(66.9) & $51(33.1)$ & & \\
\hline \multicolumn{5}{|l|}{ Education attainment } \\
\hline No formal education & $15(71.4)$ & $6(28.6)$ & 1.66 & 0.645 \\
\hline Primary & $66(57.9)$ & $48(42.1)$ & & \\
\hline Secondary & $138(62.7)$ & $82(37.3)$ & & \\
\hline Tertiary & $51(60.7)$ & $30(39.3)$ & & \\
\hline \multicolumn{5}{|l|}{ Occupation } \\
\hline Government employee & 29(61.7) & $18(38.3)$ & 3.02 & 0.389 \\
\hline Private & $91(61.1)$ & $58(38.9)$ & & \\
\hline Self employed & $90(57.7)$ & $66(42.3)$ & & \\
\hline Others & $60(69.0)$ & $27(31.0)$ & & \\
\hline \multicolumn{5}{|l|}{ Locality } \\
\hline Urban & $121(62.1)$ & 74(37.9) & 0.04 & 0.833 \\
\hline Rural & $149(61.1)$ & $95(38.9)$ & & \\
\hline \multicolumn{5}{|l|}{ Age group (Years) } \\
\hline $18-44$ & $137(65.0)$ & $118(35.0)$ & 5.31 & $<0.021$ \\
\hline 45 and above & $71(53.4)$ & $62(46.6)$ & & \\
\hline \multicolumn{5}{|l|}{ ECV User } \\
\hline Yes & $27(62.8)$ & $16(37.2)$ & 0.03 & 0.855 \\
\hline No & $243(61.4)$ & $153(38.6)$ & & \\
\hline \multicolumn{5}{|l|}{ Addiction } \\
\hline Non-low & 137(53.7) & $118(46.3)$ & 12.98 & $<0.001$ \\
\hline Moderate-High & $117(71.3)$ & $47(28.9)$ & & \\
\hline
\end{tabular}

In this study, older aged smokers (aged 45 years and above) were more likely to be in advanced stages of smoking cessation compared to their younger counterparts. This contrasts with a previous report that showed a lower proportion of older age smokers intended to cease smoking compared to smokers of younger age ${ }^{12,14}$ while a study among adult smokers in Bangladesh revealed no significant association between age and intention to cease smoking. ${ }^{33}$ The reason for our contrasting finding is probably because as people get older, they are more likely to seek medical treatment for health conditions and receive advice from health personnel about their health condition and the health effects of smoking. Studies have also shown that older people tend to be more receptive to health promotion messages and advice by health personnel, ${ }^{36}$ and the knowledge obtained therefrom might change their attitude towards smoking. ${ }^{35}$ 
Table 2: Multivariable Logistic Regression (Backward likelihood approach) to determine the association between psycho-social factors with stages of smoking cessation among Malaysian Adult smokers.

\begin{tabular}{|c|c|c|c|}
\hline Variable & Adjusted OR & $\begin{array}{l}95 \% \mathrm{Cl} \\
\text { Lower }\end{array}$ & Upper \\
\hline \multicolumn{4}{|l|}{ Gender } \\
\hline Male & 5.32 & 1.16 & 24.39 \\
\hline Female & Ref & & \\
\hline \multicolumn{4}{|l|}{ Age Group (Years) } \\
\hline $18-44$ & Ref & & \\
\hline 45 and above & 0.57 & 0.37 & 0.88 \\
\hline \multicolumn{4}{|l|}{ Addiction level } \\
\hline Non-low & Ref & & \\
\hline Moderate-High & 2.10 & 1.37 & 3.21 \\
\hline
\end{tabular}

Although smoking rates were high among the selfemployed and private sector employers, and low among government employees, ${ }^{2}$ no association was observed between occupation and stage of smoking cessation in both univariable and multivariable analysis. This finding suggests that the restriction on smoking in government facilities which was introduced in 1993 has limited influence on intention to cease smoking among government employees. ${ }^{37}$ This calls for a review of the measures to denormalise smoking among government employees. Previous studies have shown that smoking restrictions in the workplace are able to increase intention to quit and quitting rates among smoking employees. ${ }^{45}$ Higher rates of precontemplation were observed among smokers who worked in the private sector and the self-employed. This lack of motivation to quit smoking might be due smoking being common among these occupational groups. ${ }^{2,24}$

No significant association was observed between marital status and stage of smoking cessation, unlike previous studies which reported married respondents were more likely to plan to quit smoking than those who were single, widowed or divorced. The finding was also not in line with the 'marriage protection' and 'marriage selection' theories. ${ }^{38}$ These theories posit that married people receive more psychological and social support from their spouse or partner, which may help smokers deal with their problems more adaptively and make them less likely to use smoking to manage psychological stress, and therefore more likely to cease smoking. The more likely explanation is patriarchy in Malaysian households. Females and other household members would not dare to advise their smoking spouse or elders about their smoking behavior to preserve domestic harmony, ${ }^{48,49}$ Therefore smokers tend to continue their behavior due to their perception of tacit approval of their family members or spouse.

Smokers with higher nicotine addiction were more likely to be in the pre-contemplation stage compared to smokers with no or very low addiction. Other studies have revealed an inverse relationship between nicotine addiction and intention to cease smoking within 6 months 35, 39, and that precontemplators smoked more cigarettes per day than those in the contemplation or preparation stages. 12,33 Additionally, previous studies in North America and Ethiopia have shown that smokers with high cigarette consumption have lower motivation to quit smoking ${ }^{9,39,40}$ The pleasurable feeling from the release of dopamine, norepinephrine and serotonin induced by smoking, ${ }^{41,42}$ and adverse nicotine withdrawal effects experienced upon quitting, such as dysphoria or depressed mood, restlessness, insomnia, irritability, frustration, anger, craving and difficulty concentrating ${ }^{28}$, may make it more difficult to quit. This finding suggests that smoking cessation strategies should be tailored according to the smokers' nicotine addiction level.

There was no significant association between ECV use and stage of smoking cessation in univariable and multivariable analysis. This contrasted with a previous study which revealed higher likelihood of intention to quit smoking (adjusted odds ratio $\mathrm{AOR}=1.8, p=0.001$ ) among $\mathrm{ECV}$ users in a representative sample of US adults. ${ }^{43}$ Another study reported that smokers intending to quit were more likely to be e-cigarette users than those not intending to quit (odds ratio $[O R]=1.90,95 \% \mathrm{Cl}=$ 1.36-2.65). ${ }^{44}$ In another study, a significantly higher proportion of dual users intended to quit smoking in one year $(87.4 \%, 95 \% \mathrm{Cl}=83.8-90.2)$ compared to cigarette only smokers $(79.0,95 \mathrm{Cl} 76.9-81.0)^{45}$. 
This finding might be explained by several factors. Firstly, only a small proportion $(15.8 \%)$ of the current smokers in our study used e-cigarettes as a means to quit smoking compared to smokers in the US. The difference in intention might be a plausible reason, as literature has shown that behavioural intention is significantly associated with future behaviours. ${ }^{46}$ Secondly, $44 \%$ of current smokers were experimenting with ECV. Thirdly, $71 \%$ of dual users in our study preferred conventional cigarettes to ECV, and this might be due to the lower concentration of nicotine in ECV based on lab tests and the product content label. ${ }^{23}$ In addition, just prior to the survey, the Ministry of Health carried out intensive health promotion activities on the hazards of ECV and restrictions on the sale of liquids containing nicotine (can only be obtained through prescription-based sale by authorized personnel such as pharmacy), which might have contributed to the current finding.

Education attainment, residence and ethnicity were not associated with stage of smoking cessation in this study. This is surprising as education attainment (as a proxy for level of knowledge on smoking hazards) has been reported to be significantly associated with smoking cessation, with higher education correlating positively with knowledge on smoking-related health hazards, and thus influence the smokers' resolve to quit smoking. However, our findings are in line with other studies that reported no association between education and intention to quit ${ }^{18,42}$. This can be explained by the "hardening hypothesis" which suggests that less dependent smokers quit smoking and contribute to lower prevalence of smoking among certain groups in the population, and the remaining smokers form a population of "hardcore smokers".

The lack of association between intention to quit smoking among Chinese and Indian ethnic groups, and among urban residents with low prevalence of smoking since the last two decades adds weight to this theory. The finding in current study contradicted the outcome of the NHMS 2006 which revealed that all three variables were significantly associated with pre-contemplation stages of smoking cessation. ${ }^{21}$ The changing pattern of smoking among Malaysian population might partially explain the contradictory result. However, the literature on the relation between demographic characteristics and intention to quit smoking have not been consistent.

There were several limitations in the current study. Firstly, the causal relationship between stages of smoking cessation and independent variables cannot be established due to the cross-sectional study design. Secondly, the data was obtained through interview, thus are subject to recall bias.
Thirdly, intrapersonal variables such as knowledge of smoking hazard, ${ }^{47}$ mental health, ${ }^{48}$ and health status 49 of which have been shown to be significantly associated with stage of smoking were not investigated in current study. However, the findings can be generalized to the Malaysian adult population as our study involved a representative sample of Malaysian adults. In addition, the face-toface interviews were carried out by trained researchers who used a personal approach to reduce recall and under-reporting biases. The study provides the most current insight into the stage of smoking cessation among Malaysian smokers according to their social demographic, addiction level and smoking habit characteristics.

\section{CONCLUSION}

The study revealed that the majority of adult smokers were in the pre-contemplation stage of smoking cessation, therefore, population-based strategies of smoking cessation should include interventions that focus on smokers in this stage. Specific attention should be paid to precontemplators who are male, from the younger age group and smokers with high nicotine dependence. In addition, interventions to facilitate transition to the next stages should be modified according to the characteristics of the smokers. Both clinical (individual) and public health (population) approaches for treating smokers are needed, especially among those who are unwilling to attempt quitting. At the individual level, a clinician, allied health care professional can motivate smokers who are in the pre-contemplation and contemplation stages to quit smoking by presenting the benefits of quitting in regard to current and future health, emphasizing the negative consequences of tobacco use and potential benefits of quitting, identifying barriers to quitting, and discussing coping strategies.

\section{ACKNOWLEDGEMENT}

We thank the Director-General of Health Malaysia for his permission to publish this article, and the Director of the Institute for Medical Research for supporting this study.

\section{REFERENCES}

1. WHO 2015 Global health risks: mortality and burden of disease attributable to selected major risks (2015) http://www. who.int/healthinfo/global _burden_disease/GlobalHea

lthRisks_report_full.pdf.(Accessed on 28.8.2019) 
2. Institute for Public Health. National Health and Morbidity Survey 2015: Report on Smoking Status Among Malaysian Adults. Institute of Public Health, 2015.

3. Disease Control Division, Ministry of Health: Clinical Practice Guidelines. Treatment of Tobacco smoking and dependence 2002. 2003,http://www.google.com.my/url? $\mathrm{sa}=\mathrm{t} \& \mathrm{rct}=\mathrm{j} \& \mathrm{q}=\&$ tesrc $=\mathrm{s} \&$ source $=$ web\&c $\mathrm{d}=1 \&$ ved $=0$ CDIQFjAA\&url=http $\% 3 \mathrm{~A} \% 2 \mathrm{~F} \%$ 2Fwww.moh.gov.my $\% 2 F a t t a c h m e n t s \% 2$ F3996\& ei $=-$

zTtUOruLInVkwWklIC4DA\&usg $=A F Q j C N$ E_D1pUqD9Z8CmrcU53TX7DvqEWQ\&si g2=6jWFxsk8yAlhtHlqcCHjmA. (Accessed on 15 August 2019)

4. Institute of Public Health, Ministry of Health Malaysia 2004. Malaysian Burden of Disease and Injury Study, Health Prioritization: Burden of Disease Approach. Institute of Public Health, 2005.

5. Institute of Public Health, Ministry of Health Malaysia 2011. Malaysian Burden of Disease and Injury Study, Health Prioritization: Burden of Disease Approach. Institute of Public Health, 2012.

6. Ministry of Health Malaysia. (National Strategic plan for tobacco control and tobacco end game. http://jknj.moh.gov.my/ncd/strategik nsp.pdf (Accessed on 16.5.2019)

7. WHO (2003). WHO Framework Convention on Tobacco Control; 2003. Geneva. Available from: http:// whqlibdoc. who.int/ publications/2003/9241591013.pdf [accessed 26.6.2019].

8. Choi JH, Chung KM, Park K. Psychosocial predictors of four health-promoting behaviors for cancer prevention using the stage of change of Transtheoretical Model. Psychol 2013; 22:2253-2261.

9. Abughosh $\mathrm{S}, \mathrm{Wu} \mathrm{IH}$, Hawari $\mathrm{F}$, et al. Predictors of Intention to Quit Cigarette Smoking among Jordanian Adult. Epidemiol 2011; 1:2-7. Prochaska, JO, DiClemente CC, Norcross, JC. In search of how people change: Applications to the addictive behaviors. Am Psychol, 1992;47: 1102-1114.

10. Prochaska, JO, DiClemente CC, Norcross, JC. In search of how people change: Applications to the addictive behaviors. Am Psychol, 1992;47: 11021114.

11. Connors GJ,Donovan DM, DiClemente CC. 2004.Substance abuse treatment and the stage of change. Selecting and planning intervention. Guilford Press, New York, NY.

12. Jhun HJ, Seo HG. The stage of change in smoking cessation in a representative sample of Korean adult smokers. J. Korea Med Sci. 2006; 21(5): 843-848.

13. Wewers ME, Stillman FA, Hartman AM, et al. Distribution of daily smokers by stages of change:current population survey results. Prev Med. 2003; 36:710720.

14. Ma GX, Fang CY, Tan $Y$, et al. Perceptions of risks of smoking among Asian Americans. Prev Med 2003; 37: 349-355.

15. John U, Meyer C, Rumpf C, et al. Relationship between stages of changes, demographic characteristics,smoking history and nicotine dependence in an adult German population. Prev Med, 2003;37: 368-374.

16. Daoud N, Hayek S, Sheikh Muhammad $A$, et al. Stages of change of the readiness to quit smoking among a random sample of minority Arab male smokers in Israel. BMC Public Health 2015 .16;15:672.

17. Pepper JK, Brewer NT. Electronic nicotine delivery system (electronic cigarette) awareness, use, reactions and beliefs: a systematic review. Tob control 2014; 23:375-384.

18. Rutten LJF, Blake KD, Agunwamba AA, et al. Use of E-Cigarettes Among Current Smokers: Associations Among Reasons for Use, Quit Intentions, and Current Tobacco Use Nicotine Tob Res. 2015; 17 (10):1228-1234. 
19. Mathur S, Singh N. Characteristics of smokers with intentions to quit, with a focus on occupational status, race/ethnicity, and cognitive behavior. Epidemiol Biostat Public Health 2015;12:1-8

20. Slakova JN, Li JY, Crockett LJ. Race/ethnicity and intention to quit cigarette smoking. Pre Med Reports 2017; 5: 160-166

21. Lim KH, Ibrahim N, Ghazali SM, et al. Stages of smoking cessation among Malaysian adults--findings from national health morbidity survey 2006. Asian Pac J Cancer Prev.2013;14(2):805-10.

22. Institute for Public Health (IPH). Report of the Global Adult Tobacco Survey (GATS) Malaysia. 2011. Ministry of Health, Malaysia. 2012.

23. Institute for Public Health, International Islamic University Malaysia (2017). National E-Cigarette Survey (NECS) 2016: Prevalence, Pattern and Perception Regarding ECigarette and Vape use among Malaysian adults. Ministry of Health Malaysia. 2017.

24. Institute of Public Health, Ministry of Health Malaysia. Smoking. National Health and Morbidity Survey Volume 17. Kuala Lumpur: Institute of Publish Health; 2008

25. Anne Yee H.A, Ng CG, Rusdi AR Validation of the Malay Version of Fagerstrom Test for Nicotine Dependence (FTND-M) Among a Group of Male Staffs in a University Hospital.

26. Spigner C, Yip MP, Huang B, et al. Chinese and Vietnamese Adult Male Smokers' Perspectives Regarding Facilitators of Tobacco Cessation Behavior. Asian Pac J Cancer Prev 2007; 8: 429-435.

27. Campbell S. Bohanna I, Swinbourne A, et al. Stages of change, smoking behaviour and readiness to quit in a large sample of indigenous Australians living in eight remote North Queensland communities Int. J. Environ. Res. Public Health 2013
28. Feng $G$, Jiang $Y$, Li Q, et al. Individuallevel factors associated with intentions to quit smoking among adult smokers in six cities of China: findings from the ITC China Survey. Tob Cont. 2010;19(suppl 2): i6-11.

29. Mbulo L, Palipudi KM, Nelson-Blutcher $G$, et al. The process of cessation among current tobacco smokers: A cross-sectional data analysis from 21 countries, Global Adult Tobacco Survey, 2009-2013. Prev Chronic Dis 2015; 12:150146.

30. Lopez AD, Collishaw NE, Piha T. A descriptive model of the cigarette epidemic in developed countries. 1994. Tob Cont; 3:242-247.

31. California Department of Public Health California Tobacco Control Program (2008). Smokers and Quitting. Retrieved from http://www.cdph.ca.gov/programs/To bacco/Documents/CTCPFactShSmokerQuit2008.pdf(Accessed on 19.8.2019)

32. Bronfenbrenner, Urie (1999). Friedman SL and Wachs TD, ed. Measuring environment across the life span. Emerging methods and concepts. Washington, DC: American Psychological Association Press.

33. Driezen P, Abdullah AS, Anne Quah CK, et al. Determinants of intentions to quit smoking among adult smokers in Bangladesh: findings from the International Tobacco Control (ITC) Bangladesh wave 2 survey Global Health Research and Policy 2016; 1:1

34. Wong CK, Tang KL, Ye S. The perceived importance of family-friendly polices to childbirth decision among Hong Kong women. Int J Soc Welfare.2011;20:38192.

35. Lim KH, Sumarni MG, Amal, NM Hanjeet K, Wan Rozita, WM. and Norhamimah, A.Tobacco use, knowledge and attitude among Malaysians age 18 and above. Tropical Biomedicine, 2009.26(1): 9299

36. Keleher H, Parker R, Abdul Wadud $\mathrm{O}$, Francis K. Systematic review of the effectiveness of primary care nursing. International Journal of Nursing Practice, 2009, 15: 16-24. 
37. Government of Malaysia (2005). Food Act 1993: Control of Tobacco Product Regulations 2004. Available from http://www.tobaccocontrollaws.org/fi les/live/Malaysia/Malaysia\%20\%20TC\%20Regs\%202004.pdf (Accessed on 12.5.2019)

38. Mao A. Space and power: young mothers' management of smoking in extended families in China. Health Place 2013; 21:102-9.

39. Etter JF, Perneger TV, Ronchi A. Distribution of smokers by stage: International comparison and association with smoking prevalence. Prev Med 1997; 26(4):580-585.

40. Fu M, Fernandez E, Pascual AJ, et al. Stages of change, smoking characteristics, and cotinine concentrations in smokers: Setting priorities for smoking cessation. Prev Med 2011; 52:139-45.

41. Benowitz NM.Neurobiology of nicotine addiction: implications for smoking cessation treatment. $A m \quad J$ Med 2008;121(4 Suppl 1): S3-10.

42. Jiloha RC. Biological basis of tobacco addiction: implication for smoking cessation treatment. Indian J Psychiatry 2010; 52(4): 301-307.

43. Nayak P, Pechacek TF, Weaver SR, et al. Electronic nicotine delivery system dual use and intention to quit smoking: Will the socioeconomic gap in smoking get greater? Addict Behav 2016; 61:112-116.

44. Rutten LJ, Blake KD, Agunwamba AA, Grana RA, Wilson PM, Ebbert JO, Okamoto J, Leischow SJ.Use of ECigarettes Among Current Smokers: Associations among reasons for use, quit intentions, and current tobacco use. Nicotine Tob Res. $2015 ; 17(10): 1228-1234$

45. Rostron BL, Megan J. Schroeder MJ, Ambrose BK. Dependence symptoms and cessation intentions among US adult daily cigarette, cigar, and ecigarette users, 2012-2013. BMC Public Health (2016) 16:814Mohammadpoorasl A, Nedjat S, Yazdani K, et al. Intention to start smoking and its related factors in never smoked adolescents in tabriz,
2010. Int J Prev Med. 2012;3(12):880886.

46. Mohammadpoorasl A, Nedjat S, Yazdani $\mathrm{K}$, et al. Intention to start smoking and its related factors in never smoked adolescents in tabriz, 2010. Int J Prev Med. 2012;3(12):880-886.

47. Wu TY, Chie WC, Chen CC, Kuo KL, Majeed A. Knowledge of the new tobacco hazards prevention act is associated with smokers' behaviour of seeking help in smoking cessation in Taiwan. Asia Pacific Journal of Public Health 2015. 27(2):212-222.

48. Bond L, Egan M, Kearns A, et al. Smoking and intention to quit in deprived areas of Glasgow: Is it related to housing improvements and neighbourhood regeneration because of improved mental health? J Epidemiology Community Health 2013; 67(4): 299-304.

49. Marques-Vidal $P$, Melich-Cerveira J, Paccaud F, Waeber G, Vollenweider P, Cornuz J. Prevalence and factors associated with difficulty and intention to quit smoking in Switzerland. BMC Public Health. 2011. 